\title{
Screening of Antidepressant Activity and Marker-based Standardization of Baptisia tinctoria (L.) R. Vent.
}

RICHA D. KUMAR AND S. KUMAR*

Department of Pharmaceutical Sciences and Drug Research, Punjabi University, Patiala-147 002, India

\author{
Richa and Kumar: Antidepressant Activity and TLC Densitometry of Baptisia tinctoria
}

\begin{abstract}
Baptisia tinctoria (Wild indigo; Fabaceae) has long tradition of use in Indian systems of medicine for the treatment of depression. This investigation deals with the evaluation of the antidepressant activity of various extracts and fractions of $B$. tinctoria roots and estimation of the content of bioactive principle using thin-layer chromatography densitometry. Roots of $\boldsymbol{B}$. tinctoria were successively extracted to obtain n-hexane, chloroform, methanol and water extracts. The chloroform, methanol and water extracts were screened for antidepressant activity at doses of 200 or $400 \mathrm{mg} / \mathrm{kg}$, p.o., in mice subjected to forced swim test. Methanol extract showed significant activity at a dose of $400 \mathrm{mg} / \mathrm{kg}$. The methanol extract was further fractionated successively to obtain ethyl acetate and 1-butanol fractions. Antidepressant activity of these fractions was assessed using forced swim test at the doses of 90 and $80 \mathrm{mg} / \mathrm{kg}$, p.o., respectively. The ethyl acetate fraction showed significant antidepressant activity at the dose of $90 \mathrm{mg} / \mathrm{kg}$ in mice. Further, specific antidepressant activity without psychostimulant effects of bioactive methanol extract and ethyl acetate fraction was confirmed through evaluation of locomotor behaviour in mice using open field test. Phytochemical screening showed the presence of flavonoids as major class of phytoconstituents in the methanol extract. Comparative thin-layer chromatography fingerprint studies confirmed the presence of hesperitin in methanol extract. Hesperitin was used as a chemical marker to standardize $B$. tinctoria roots using validated thin-layer chromatography densitometric method and the content of hesperitin was found to $\mathrm{be} \mathbf{0 . 0 0 8 5} \% \mathrm{w} / \mathrm{w}$.
\end{abstract}

Key words: Antidepressant, Baptisia tinctoria, Fabaceae, TLC densitometry, wild indigo

Depression is a state of low mood and aversion to activity that can affect a person's thoughts, behaviour, feelings and sense of well-being. Approximately $15 \%$ of the population experiences a major depressive episode at some point of life ${ }^{[1]}$. Research also suggests that maternal depression may be a risk factor for poor growth in young children ${ }^{[2]}$. Depression is a significant contributor to the global burden of disease and affects people in all communities across the world ${ }^{[3]}$. It is estimated that about 350 million people worldwide suffer from depression. The World Mental Health Survey conducted in 17 countries found that on average about 1 in 20 people reported having an episode of depression in the previous year. Depressive disorders often start at a young age; they reduce people's functioning and often are recurring. The pharmacotherapy of depression includes tricyclic antidepressants, tetracyclic antidepressants, monoaminoxidase inhibitors and selective serotonin reuptake inhibitors ${ }^{[4,5]}$. These antidepressant drugs

*Address for correspondence E-mail: thakur_pu@yahoo.com

May-June 2017 frequently produce side effects such as dry mouth, mydriasis, constipation, temporary fatigue, restlessness and headaches ${ }^{[6]}$. The increased risk of side-effects, drug-drug and drug-food interactions have raised the need for efficacious and relatively safer drugs to cure depression. In the light of adverse effects associated with these synthetic drugs, researchers worldwide are searching for newer, safer and more efficacious alternatives $^{[7,8]}$. Herbs prove to be useful, safe and potent therapeutic agents to treat various CNS disorders including depression ${ }^{[9]}$. A wide variety of plants exist in nature popularly reputed to have medicinal properties. Baptisia tinctoria (L.) R. Vent. is one of such plants.

This is an open access article distributed under the terms of the Creative Commons Attribution-NonCommercial-ShareAlike 3.0 License, which allows others to remix, tweak, and build upon the work non-commercially, as long as the author is credited and the new creations are licensed under the identical terms

Accepted 18 April 2017

Revised 04 January 2017

Received 23 August 2016

Indian J Pharm Sci 2017;79(3):395-401 
B. tinctoria (Wild Indigo; family-Fabaceae) is indicated in wandering feeling, inability to think, mental confusion, delirium, melancholia with stupor and threatened miscarriage from mental depression ${ }^{[10-12]}$. The plant has been reported to contain various groups of phytoconstituents- alkaloids, phenols, flavonoids, coumarins and triterpenes. The polysaccharides isolated from $B$. tinctoria, showed significant immune stimulating activity as assessed by the in vitro granulocyte test and in vivo carbonclearance test ${ }^{[13]}$. Glycoproteins and arabinogalactan proteins of the plant stimulated enhanced secretion of the endogenous immunostimulant interleukin ${ }^{[14]}$. B. tinctoria showed significant phagocytic activity in the granulocyte carbon-clearance tests when administered in combination with Echinacea angustifolia DC. ${ }^{[15]}$. Literature search revealed that $B$. tinctoria has not been scientifically investigated for antidepressant activity. Thus, it was planned to investigate antidepressant activity of various extracts and fractions of $B$. tinctoria roots and to estimate the content of hesperitin in the plant using thin-layer chromatography (TLC) densitometry.

\section{MATERIALS AND METHODS}

B. tinctoria roots were procured form Himalaya Herbs Store, Madhav Nagar, Saharanpur, UP, India in September, 2015. The plant was identified in the Department of Botany, Punjabi University, Patiala, India (Reference No. SPL-105/Bot, dated 12-102015). LR grade solvents, $n$-hexane, chloroform, methanol, ethyl acetate, 1-butanol procured from $\mathrm{E}$ Merck, Delhi, India, were used for the preparation of plant extracts and fractions. Toluene, ethyl acetate, methanol and glacial acetic acid, of AR grade were employed for TLC studies. Quercetin, naringenin, hesperitin, apigenin, and chrysin procured from SigmaAldrich Company, St. Louis MO, USA were used for establishing TLC fingerprint profiles. Instruments used were, rotary vacuum evaporator (Buchi, Switzerland), digital weighing balance (Ohaus, USA), hot air oven (Universal Instrument, Bangalore, India), Soxhlet apparatus, water bath (Perfit, Ambala, Haryana, India), TLC densitometer (Camag, Switzerland) and UV Light Chamber (254/366 nm, Gupta Scientific Store, Ambala, Haryana, India) were used to perform experiments of present research work. TL chromatograms were taken on the precoated aluminium based TLC plates (E Merck, Delhi, India).

\section{Preparation of extracts and fractions:}

The roots of $B$. tinctoria were powdered in a grinder. Dried powdered plant material $(0.5 \mathrm{~kg})$ was placed in thimble, made up of fine filter paper. The plant was then extracted in a Soxhlet apparatus with $n$-hexane (2 1) exhaustively till few drops collected from siphoning tube on watch glass did not leave any residue after evaporation. The marc was dried, packed in a thimble and extracted exhaustively in a Soxhlet apparatus using chloroform (2 1) to get chloroform extract (CE). After complete extraction with chloroform, the same procedure was adopted to get methanol extract (ME) using methanol (2 1). The water extract (WE) was prepared by boiling the marc of plant material with distilled water $(21)$ for $2 \mathrm{~h}$ on a hot plate. The solvents from crude extracts were recovered under reduced pressure using a rotary vacuum evaporator to get $n$-hexane extract (HE), CE, ME and WE.

The ME (25 g) was taken in a round bottom flask, and $50 \mathrm{ml}$ of distilled water was added to the extract. A suspension of the extract in distilled water was prepared by triturating the material for 30 min with a glass rod. It was then partitioned with $50 \mathrm{ml}$ of ethyl acetate by heating at $50^{\circ}$ for $30 \mathrm{~min}$ along with continuous stirring. The contents were cooled and ethyl acetate layer (upper layer) was separated. To the extract $50 \mathrm{ml}$ of fresh ethyl acetate was added and the procedure was repeated Fractional extraction with ethyl acetate was repeated till a few $\mathrm{ml}$ of ethyl acetate layer did not leave any significant residue on a watch glass after evaporation. All the separated layers of ethyl acetate were pooled and concentrated under reduced pressure to finally obtain ethyl acetate fraction (EAF). Similar procedure was adopted on the remaining bioactive extract (RBE) to get 1-butanol fraction (BF). After successive partitioning with ethyl acetate and 1-butanol, the RBE was also concentrated. All the extracts of plant and fractions of the bioactive extract were screened for the presence of various groups of phytoconstituents ${ }^{[16]}$.

\section{Antidepressant activity:}

Laca mice (either sex, body weight 20-25 g) were used for pharmacological activities. The animals were purchased from the Central Research Institute, Kasauli, India. Normal laboratory pellet diet and water $a d$ libitum were given to mice. The approval was taken from Institutional Animal Ethics Committee (IAEC) of Punjabi University, Patiala before carrying out animal studies (107/99/CPCSEA-2016-30, dated 
27-05-2016). Animals were acclimatized to laboratory conditions daily for $1 \mathrm{~h}$ for seven days before starting the experiment. Groups of six animals were used in all sets of experiments. The test drugs were administered orally with the help of an oral cannula fitted on a tuberculin syringe. The antidepressant and locomotor activity studies were investigated using well established models such as forced swim test (FST) and open field test, respectively, as per standard procedures ${ }^{[9]}$. Distilled water+Tween $80(2 \%)$ was used as a vehicle for preparing various test doses of crude extracts, fractions and the standard drug. Imipramine (Triko Pharmaceuticals, Rohtak, Haryana, India; 15 $\mathrm{mg} / \mathrm{kg}$, p.o.), was used as standard antidepressant drug.

\section{Experimental protocol:}

Three experimental protocols were designed consisting of 16 groups of mice. Experimental protocol I, comprising groups 1 to 8 , was designed to assess antidepressant activity of various crude extracts of B. tinctoria roots. Control group (group 1) received vehicle $(0.25 \mathrm{ml}$, p.o. $)$; standard group (group 2) received imipramine (15 mg/kg, p.o.); test group 3 and 4 received 200 and $400 \mathrm{mg} / \mathrm{kg}$ doses of CE, respectively; test group 5 and 6 received 200 and $400 \mathrm{mg} / \mathrm{kg}$ doses of ME, respectively and test groups 7 and 8 received 200 and $400 \mathrm{mg} / \mathrm{kg}$ doses of WE.

Experimental protocol II, comprising groups 9 to 12, was designed to assess antidepressant activity of various fractions of $B$. tinctoria roots. Control group (group 9) received vehicle $(0.25 \mathrm{ml}$, p.o.); standard group (group 10) received imipramine $(15 \mathrm{mg} / \mathrm{kg}$, p.o.); test group (group 11) received $90 \mathrm{mg} / \mathrm{kg}$ dose of EAF and test group 12 received $80 \mathrm{mg} / \mathrm{kg}$ dose of BF.

Experimental protocol III, comprising groups 13 to 16, was designed to assess locomotor activity of bioactive extract and fraction of $B$. tinctoria roots. Control group (Group 13) received vehicle $(0.25 \mathrm{ml}$, p.o. $)$; standard group (group 14) received imipramine $(15 \mathrm{mg} / \mathrm{kg}$, p.o.); test group (group 15) received $400 \mathrm{mg} / \mathrm{kg}$ dose of $\mathrm{ME}$ and test group 16 received $90 \mathrm{mg} / \mathrm{kg}$ dose of EAF.

\section{Statistical analyses:}

The results were expressed as mean \pm standard deviation (SD). The test samples were compared with standard drug and control by one way analysis of variance (ANOVA) followed by Student Newman Keul's test ${ }^{[17]}$.

\section{TLC fingerprint profiles:}

A fixed volume, $5 \mu 1$ of bioactive extract of the plant and standard flavonoids was applied on $20 \times 10 \mathrm{~cm}$ precoated TLC plate using Camag Linomat 5. The plate was developed using solvent system, toluene:ethyl acetate:glacial acetic acid (15:11:2) in a TLC chamber, to a distance of $8 \mathrm{~cm}$. The plate was dried under the current of hot air and visualised under ultraviolet light (254 $\mathrm{nm}$ and $366 \mathrm{~nm}$ ) in a UV/Vis cabinet.

\section{TLC densitometric method development studies:}

The coarsely powdered root (10 g) was exhaustively extracted with methanol in a Soxhlet apparatus as described earlier. The extract was filtered, concentrated under reduced pressure and the volume was adjusted to $10 \mathrm{ml}$ with methanol. Accurately weighed quantity of the marker compound ( $5 \mathrm{mg}$ ) was dissolved in $5 \mathrm{ml}$ of methanol. The stock solution of the marker compound was diluted with methanol to get six dilutions of different concentrations $(4,8,12,16,20$ and $24 \mu \mathrm{g} / \mathrm{ml})$. An aliquot of $10 \mu \mathrm{l}$ from each dilution was applied, in triplicate, on a pre-coated TLC plate. The plate was developed in the solvent system, toluene:ethyl acetate:methanol (10:7:3) in a chamber, to a distance of $8 \mathrm{~cm}$. The developed plate was dried in a current of hot air and then scanned in a Camag TLC scanner at $278 \mathrm{~nm}$. The AUC of the peak corresponding to marker compound was noted in each track.

Test solutions $(10 \mu \mathrm{l})$ of ME was applied in triplicate on a pre-coated TLC plate $(5 \times 10 \mathrm{~cm})$. The plate was developed and scanned following the same procedure as described previously. The average AUC of the peak corresponding to marker compound was noted at $278 \mathrm{~nm}$ in the test sample and its concentration was calculated from the standard plot. The developed TLC densitometric method was validated for the parameters such as linearity, range, limit of detection, limit of quantification, inter-day precision, intra-day precision, accuracy, repeatability and specificity as per ICH guidelines $^{[9]}$.

\section{RESULTS AND DISCUSSION}

Percent yields of HE, CE, ME and WE were found to be $0.40,2.32,13.02$ and $5.00 \% \mathrm{w} / \mathrm{w}$, respectively. The results of chemical tests of various extracts showed fixed oils in HE; alkaloids, steroids, triterpenoids and coumarins in CE; proteins, carbohydrates, flavonoids, tannins and coumarins in ME; proteins, carbohydrates and tannins in WE. It is clearly evident from the results of phytochemical screening that HE did not show presence of any main class of phytoconstituents. Therefore, only CE, ME and WE were screened for 
antidepressant activity in mice using FST. In this test, mice are forced to swim in a limited area from which they cannot escape. Initially, mice try to escape from the restricted space and remain in mobile state. After few seconds, mice adapt to characteristic behaviour of immobility. The duration of immobility is recorded as assessment parameter of antidepressant activity of the test substances ${ }^{[18]}$. The duration of immobility exhibited by mice after acute administration of 200 or $400 \mathrm{mg} /$ $\mathrm{kg}$, p.o., doses of crude extracts, imipramine $(15 \mathrm{mg} /$ $\mathrm{kg}$, p.o.) and the control (vehicle, p.o.) is shown in Table 1. Amongst various extracts, only ME exhibited significant antidepressant activity with respect to control. Though the ME (200 mg/kg) significantly reduced immobility time in mice with respect to control, but could not produce activity comparable to that produced by imipramine. At a higher dose of 400 $\mathrm{mg} / \mathrm{kg}$, the effect produced by ME was similar to that produced by imipramine. It is clearly evident from Table 1 that ME significantly reduced time spent by the mice in the immobile state (antidepressant activity) at the dose of $400 \mathrm{mg} / \mathrm{kg}$, which is statistically not different to that shown by the mice treated with imipramine. WE was found to be devoid of antidepressant activity whereas $\mathrm{CE}$ exhibited mild antidepressant activity. $\mathrm{CE}$ of plant significantly reduced duration of immobility in mice at the doses of 200 or $400 \mathrm{mg} / \mathrm{kg}$ with respect to control, which is much lower than that produced by imipramine. These results demonstrate that the $\mathrm{ME}$ is the most active extract of $B$. tinctoria roots.

The bioactive ME was fractionated successively using solvents in order of increasing polarity, ethyl acetate and 1-butanol for further fractionation. Percent yields of EAF, BF and RBE were found to be 22.45, 19.92 and $57.63 \% \mathrm{w} / \mathrm{w}$, respectively, in relation to $\mathrm{ME}$. Phytochemical screening of various fractions showed presence of flavonoids, tannins and coumarins in EAF; proteins, carbohydrates, tannins and coumarins in BF; proteins and carbohydrates in RBE. It was clearly evident from results of phytochemical screening that RBE did not show presence of any main class of phytoconstituents. Therefore, EAF and BF were further screened for antidepressant activity in mice using FST. Based on relative percentage yields of $\mathrm{EAF}$ and $\mathrm{BF}$ to the $\mathrm{ME}$, a single dose of fractions was selected for antidepressant activity evaluation. Table 2 showed the mean time spent by mice in immobile state after administration of EAF (90 mg/kg, p.o.), BF (80 mg/kg, p.o.), imipramine (15 $\mathrm{mg} / \mathrm{kg}$, p.o.) and the control (vehicle, p.o.). Only EAF exhibited significant antidepressant activity at the dose of $90 \mathrm{mg} / \mathrm{kg}$ with respect to control and the activity was statistically equivalent to that of imipramine. $\mathrm{BF}$ reduced significantly immobility time in when compared to the control, but this reduction is much lower than that produced by imipramine. This observation confirms mild antidepressant activity of BF.

The exploratory behaviour of mice in terms of number of squares crossed and rearings in open field apparatus was observed to assess locomotor activity of ME (400 mg/kg, p.o.), EAF (90 mg/kg, p.o.), imipramine (15 mg/kg, p.o.) and the control (vehicle, p.o.). ME and EAF did not exhibit any effect on the number of crossing and rearing in the open field test at

TABLE 1: ANTIDEPRESSANT ACTIVITY OF CRUDE EXTRACTS OF B. TINCTORIA ROOTS USING FST

\begin{tabular}{ccc}
\hline Treatment & Dose $(\mathrm{mg} / \mathrm{kg})$ & Mean $^{\mathrm{n}}$ immobility time $(\mathrm{s}) \pm$ SD \\
\hline Control & Vehicle & $278.00 \pm 8.78^{\mathrm{a}}$ \\
Imipramine & 15 & $62.33 \pm 9.20^{*}$ \\
CE & 200 & $169.17 \pm 10.68^{* \mathrm{a}}$ \\
& 400 & $130.00 \pm 8.94^{* \mathrm{a}}$ \\
ME & 200 & $85.83 \pm 10.20^{* \mathrm{a}}$ \\
& 400 & $65.00 \pm 8.94^{*}$ \\
WE & 200 & $266.83 \pm 7.91^{\mathrm{a}}$ \\
& 400 & $269.16 \pm 14.28^{\mathrm{a}}$ \\
\hline
\end{tabular}

$\mathrm{n}=6$; ${ }^{*} \mathrm{P}<0.05$ vs. control; a $<<0.05$ vs. imipramine; one way ANOVA followed by Student-Newman-Keul's test. FST: forced swim test, $\mathrm{CE}$ : chloroform extract, $\mathrm{ME}$ : methanol extract, WE: water extract

TABLE 2: ANTIDEPRESSANT ACTIVITY OF VARIOUS FRACTIONS OBTAINED FROM BIOACTIVE ME OF $B$. TINCTORIA ROOTS USING FST

\begin{tabular}{ccc}
\hline Treatment & Dose $(\mathbf{m g} / \mathbf{k g})$ & Mean $^{\mathrm{n}}$ immobility time $(\mathbf{s}) \pm$ SD \\
\hline Control & Vehicle & $278.33 \pm 11.25^{\mathrm{a}}$ \\
Imipramine & 15 & $63.33 \pm 5.20^{*}$ \\
EAF & 90 & $62.66 \pm 5.24^{*}$ \\
BF & 80 & $163.16 \pm 10.77^{* a}$ \\
\hline
\end{tabular}

$\mathrm{n}=6$; ${ }^{\mathrm{P}}<0.05$ vs. Control; a $\mathrm{P}<0.05$ vs. imipramine; one way ANOVA followed by Student-Newman-Keul's test. FST: forced swim test, EAF: ethyl acetate fraction; BF: 1-butanol fraction 


\begin{tabular}{lccc}
\hline Treatment Group & Dose $(\mathrm{mg} / \mathrm{kg})$ & Mean $^{\mathrm{n}}$ number of squares crossed \pm SD & Mean $^{\mathrm{n}}$ number of rearings \pm SD \\
\hline Control & Vehicle & $57.85 \pm 7.01$ & $16.24 \pm 2.99$ \\
Imipramine & 15 & $56.87 \pm 6.58$ & $16.05 \pm 3.87$ \\
ME & 400 & $58.44 \pm 7.88$ & $17.10 \pm 3.25$ \\
EAF & 90 & $57.25 \pm 8.49$ & $16.74 \pm 2.01$
\end{tabular}

$\mathrm{n}=6$; one way ANOVA followed by Student-Newman-Keul's test. ME: methanol extract; EAF: ethyl acetate fraction

400 and $90 \mathrm{mg} / \mathrm{kg}$, respectively (Table 3). ME and EAF did not show any effect on locomotor activity of mice in open field test, thus, suggested that the decrease in the immobility elicited by ME and EAF in the FST was not related to a psychostimulant effect. These observations confirmed specific antidepressant activity of ME of B. tinctoria roots, and it's EAF.

Several studies reported that flavonoids exhibited CNS activities ${ }^{[19]}$. Therefore, an attempt was made to characterize crude $\mathrm{ME}$ of $B$. tinctoria roots by comparing TLC profiles of reference flavonoids (quercetin, naringenin, hesperitin, apigenin, chrysin) with crude extract. The results of comparative TLC studies showed that ME contains hesperitin. Hesperitin is being reported for the first time in this plant. A perusal of literature revealed that hesperitin and its glycoside hesperidin exhibited strong antidepressant activity. Hesperidin has been reported to exhibit antidepressant activity at acute and chronic doses of $0.1,0.3$ or $1 \mathrm{mg} /$ $\mathrm{kg}$, i.p., and this effect appeared to be mediated by the inhibition of 1-arginine-NO-cGMP pathway and elevation of BDNF levels in hippocampus ${ }^{[20]}$. The antidepressant activity of hesperidin has been reported at the doses of $0.1,0.3$ or $1 \mathrm{mg} / \mathrm{kg}$, i.p., using FST and tail suspension test via interaction with the $\kappa$-opioid receptor and serotonergic $5-\mathrm{HT}(1 \mathrm{~A})$ receptors $^{[21,22]}$. In an another study, antidepressant activity of hesperidin was reported at the dose of $0.7 \mathrm{mg} / \mathrm{kg}$, i.p. using FST ${ }^{[23]}$. These reports support the conclusion that hesperitin, found to be one of the constituents of B. tinctoria roots could be responsible for the antidepressant effects of the plant. Thus, hesperitin was taken as a chemical marker to standardize B. tinctoria using validated TLC densitometric method.

Comparative fingerprint profile of $\mathrm{ME}$ and hesperitin of $B$. tinctoria roots visualized under ultraviolet light at $254 \mathrm{~nm}$ is presented in fig. 1. A standard plot was prepared between different concentrations of hesperitin and their peak areas after scanning at $278 \mathrm{~nm}$ (fig. 2). Linearity of calibration plot of hesperitin was achieved between 40 to $240 \mathrm{ng}$. The content of hesperitin in B. tinctoria roots was found to be $0.0085 \pm 0.00002 \%$ w/w. ICH guidelines were followed to validate the

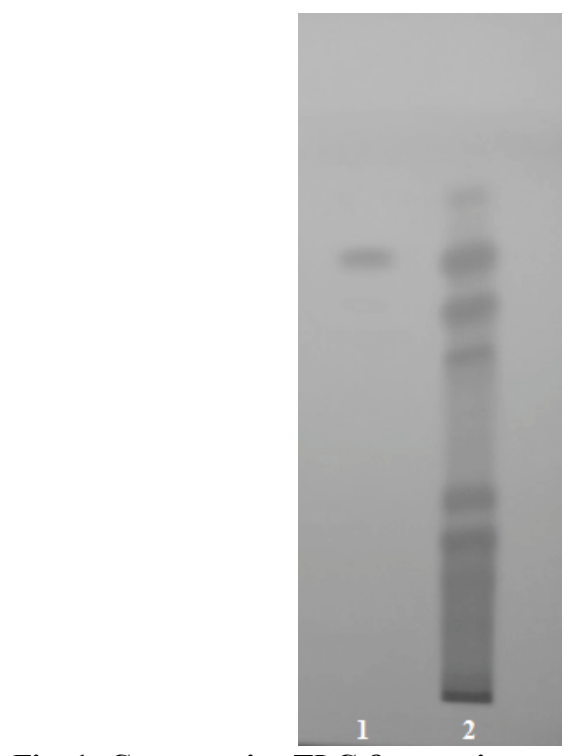

Fig. 1: Comparative TLC fingerprint profile of hesperitin and ME of $B$. tinctoria roots

The chromatogram was visualized under ultraviolet light at 254 nm. Lane 1 is hesperitin and lane 2 is methanol extract (ME)

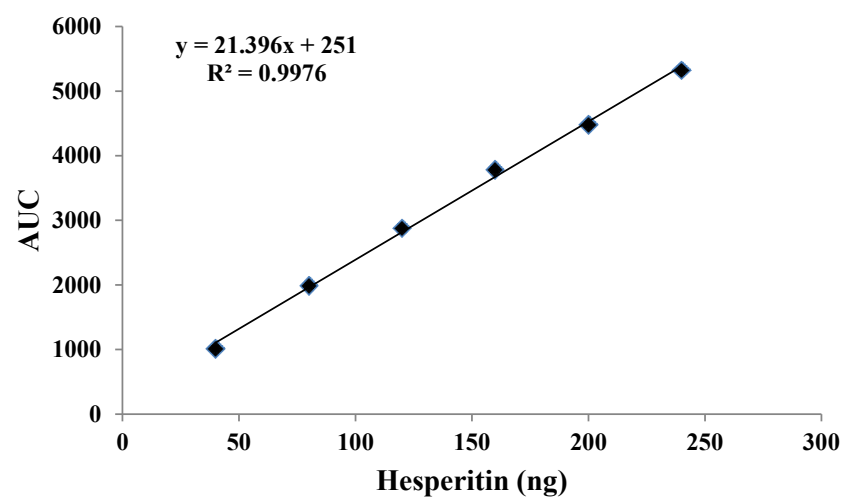

Fig. 2: Standard plot of hesperitin in TLC densitometric analysis

developed TLC densitometric method for estimation of hesperitin in B. tinctoria roots. The prescribed limits of validation parameters such as instrumental precision, intra and inter-day precision and repeatability are less than 2\% CV (Tables 4 and 5). When thin layer chromatograms (fig. 3) and UV spectra (fig. 4) overlays of standard and sample were studied, no interference was observed. This observation inferred that developed TLC densitometric method was specific for estimation of hesperitin. In accuracy studies, average recovery was found to be $98.9 \%$. These observations infer that 


\begin{tabular}{cc}
\hline Parameter & Hesperitin \\
\hline Instrumental precision $(\% \mathrm{CV}, \mathrm{n}=7)$ & 0.55 \\
Repeatability $(\% \mathrm{CV}, \mathrm{n}=5)$ & 0.10 \\
Coefficient of determination $\left(\mathrm{r}^{2}\right)$ & 0.9976 \\
Linearity range $(\mathrm{ng})$ & $40-240$ \\
LOD (ng) & 4 \\
LOQ (ng) & 14 \\
Intra-day precision (\% CV, n=9) & 0.40 \\
Inter-day precision (\% CV, $\mathrm{n}-=9)$ & 0.55 \\
Accuracy (average \% recovery) & 98.90 \\
Specificity & Specific \\
\hline
\end{tabular}

TABLE 5: RECOVERY STUDIES OF HESPERITIN

\begin{tabular}{|c|c|c|c|c|c|}
\hline Compound & $\begin{array}{c}\text { Amount of marker } \\
\text { present }(\mu \mathrm{g})\end{array}$ & $\begin{array}{c}\text { Amount of marker } \\
\text { added }(\mu \mathrm{g})\end{array}$ & $\begin{array}{l}\text { Amount of marker found } \\
(\mu \mathrm{g})\left(\text { mean }^{n} \pm \text { SD }\right)\end{array}$ & $\begin{array}{l}\text { Recovery } \\
\text { (\%) }\end{array}$ & $\begin{array}{l}\text { Average recovery } \\
\text { (\%) }\left(\text { mean }^{n} \pm S D\right)\end{array}$ \\
\hline \multirow{3}{*}{ Hesperitin } & 170 & $136(80 \%)$ & $302.41 \pm 1.95$ & 98.83 & \\
\hline & 170 & 170 (100\%) & $335.65 \pm 2.64$ & 98.72 & $98.90 \pm 0.23$ \\
\hline & 170 & $204(120 \%)$ & $370.86 \pm 3.47$ & 99.16 & \\
\hline
\end{tabular}

Each determination was in triplicate; quantity of marker was found was equivalent to $2 \mathrm{~g}$ plant material taken

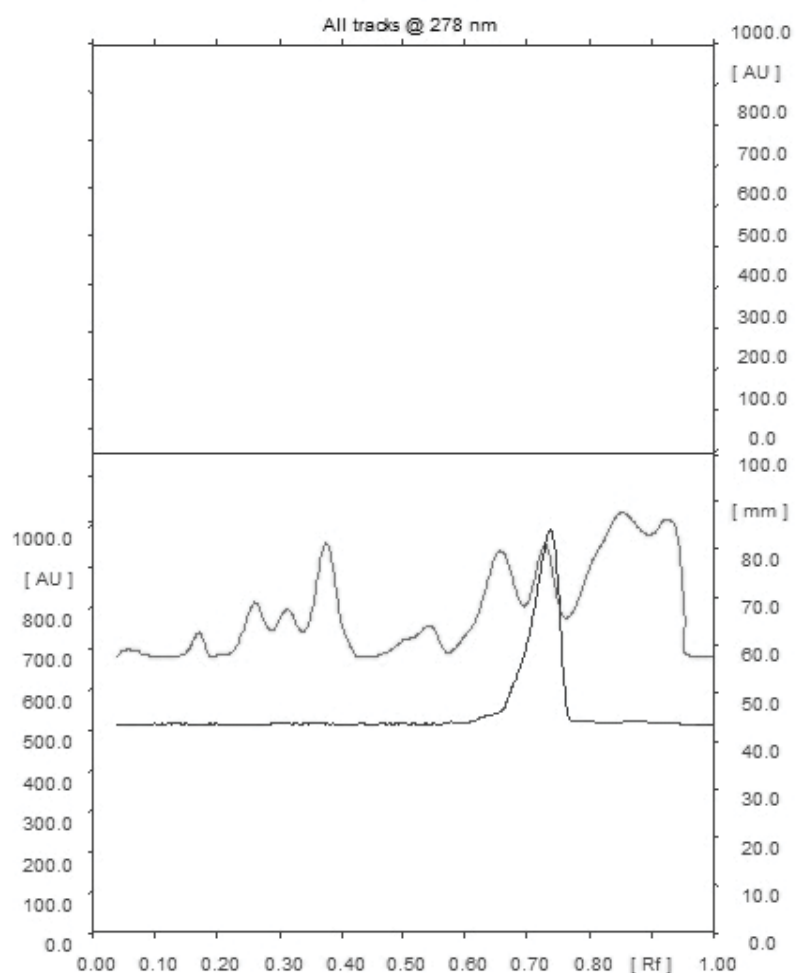

Fig. 3: TLC densitometric chromatogram of hesperitin and ME of B. tinctoria roots

the developed method for estimation of hesperitin in B. tinctoria roots is precise, accurate, reproducible and specific.

\section{Acknowledgement:}

Authors duly acknowledge Prof. R. C. Gupta, Coordinator of DBT-IPLS project for providing access to instrumentation facilities at Punjabi University, Patiala

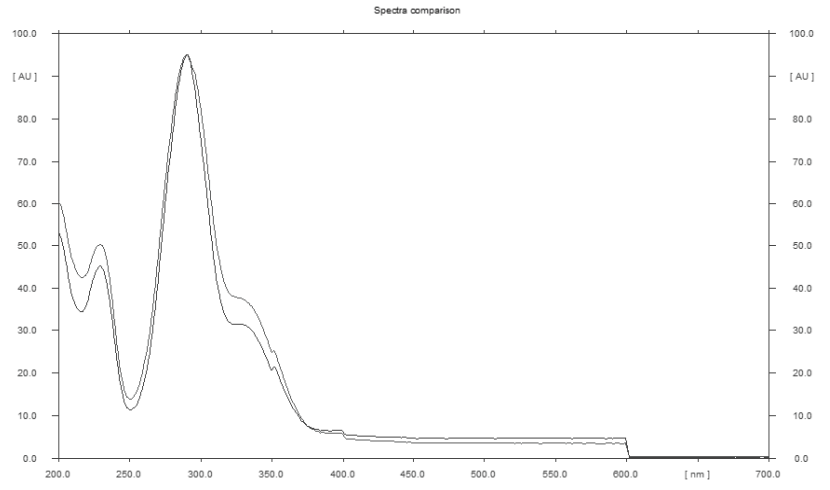

Fig. 4: Spectra overlay of hesperitin with corresponding peak in ME of $B$. tinctoria roots

and thank Dr. Avneet Pal Singh, Assistant Professor, Department of Botany, Punjabi University, Patiala for authenticating the plant material.

\section{Conflict of interest:}

The authors declare no conflict of interest with respect to this work.

\section{Financial support and sponsorship:}

Nil.

\section{REFERENCES}

1. Kendler KS, Gardner CO, Neale MC, Prescott CA. Genetic risk factors for major depression in men and women: similar or different heritabilities and same or partly distinct genes. Physiol Med 2001;31:605-16.

2. Rahman A, Patel V, Maselko J, Kirkwood B. The neglected ' $\mathrm{m}$ ' in MCH programmes - why mental health of mothers is important for child nutrition. Trop Med Int Health 2008; 13:579-83. 
3. http://www.who.int/mental_health/management/depression/ wfmh_paper_depression_wmhd_2012.pdf.

4. Baldessarini RJ. Drugs and the treatment of psychiatric disorders. In: Hardman JG, Limbird, LE, Gilman AG, editors. Goodman and Gilman's The Pharmacological Basis of Therapeutics. New York: McGraw-Hill; 2001. p. 987-96.

5. Majeroni BA, Hess AD. The pharmacologic treatment of depression. J Am Board Fam Med 1998;11:127-39.

6. Dziukas LJ, Vohra J. Tricyclic antidepressant poisoning. Med J Aus 1991;154:344-50.

7. Arnold AH, Gulumian M. Pharmacopoeia of traditional medicine in Venda. J Ethnopharmacol 1984;12:35-74.

8. Zolla C. Traditional medicine in Latin American with particular reference to Mexico. J Ethnopharmacol 1980;2:37-51.

9. Randhawa K, Kumar D, Jamwal A, Kumar S. Screening of antidepressant activity and estimation of quercetin from Coccinia indica using TLC densitometry. Pharm Biol 2015;53:1867-74.

10. Bergner P. Nervous depression and homeopathic indications of herbs. Med Herb 1995;9:12.

11. http://www.homeoint.org/books/boericmm/b/bapt.html.

12. http:/www.herbaltransitions.com/materiamedica/Baptisia. html.

13. Wagner H, Proksch A, Riess-Maurer I, Vollmar A, Odenthal S, Stuppner $\mathrm{H}$, et al. Immunostimulant action of polysaccharides (heteroglycans) from higher plants. Med Res 1984;34:659-61.

14. Beuscher N, Beuscher HU, Bodinet C. Enhanced Release of Interleukin-1 from mouse macrophages by glycoprotein and polysaccharides from Baptisia tinctoria and Echinacea species. Planta Med 1989;55:660.

15. Wagner H, Jurcic K. Immunological studies of plant extract combination/in vitro and in vivo studies on the stimulation of phagocytosis. Med Res 1991;41:1072-6.
16. Farnsworth NR. Biological and chemical screening of plants. J Pharma Sci 1966;55:225-76.

17. Scheffer WC. Statistics for the biological sciences. 32nd ed. Philippines: Addison-Wesley Publishing Company; 1980. p. 121-41.

18. Weiss JM, Goodman PA, Losito GO, Corrigan S, Carris JM, Bailey WH. Behavioural depression produced by uncontrollable stressor: Relationship to norepinephrine, dopamine and serotonin levels in various regions of rat brain. Brain Res 1981;3:167-205.

19. Butterweck V, Jurgenliemk G, Nahrstedt A, Winterhoff H. Flavonoids of Hypericum perforatum show antidepressant activity in forced swim test. Planta Med 2000;66:291-5.

20. Donato F, de Gomes MG, Goes AT, Filho CB, Del Fabbro $\mathrm{L}$, Antunes MS, et al. Hesperidin exerts antidepressant-like effects in acute and chronic treatments in mice: possible role of 1-arginine-NO-CGMP pathway and BDNF levels. Brain Res Bull 2014;104:19-26.

21. Filho CB, Del Fabbro L, de Gomes MG, Goes AT, Souza LC, Boeira SP, et al. Kappa-opioid receptors mediate the antidepressant-like activity of hesperidin in the mouse forced swimming test. Eur J Pharmacol 2013;698:286-91.

22. Souza LC, de Gomes MG, Goes AT, Del Fabbro L, Filho CB, Boeira SP, et al. Evidence for the involvement of the serotonergic 5-HT(1A) receptors in the antidepressant-like effect caused by hesperidin in mice. Prog Neuropsychopharmacol Biol Psych 2013;40:103-9.

23. Herrera-Ruiz M, Zamilpa A, Gonzalez-Cortazar M, ReyesChilpa R, Leon E, Garcia MP, et al. Antidepressant effect and pharmacological evaluation of standardized extract of flavonoids from Byrsonima crassifolia. Phytomedicine 2011;18:1255-61. 